\title{
A BEHAVIORAL MODEL FOR THE OBSIDIAN INDUSTRY OF CHIAPA DE CORZO
}

\author{
John E, ClinkK \\ Thomas A. LeE, JR. \\ Fundación Arqueológica del \\ Nuevo Mundo \\ BYU
}

\section{Introduction}

This paper discusses the reanalysis of the obsidian artifacts from the site of Chiapa de Corzo, Chiapas, Mexico. The artifacts were recovered during 6 years of excavation and investigation of the site by the New World Archaeological Foundation. The artifacts have been described previously (Lee, 1969); however, since the time of their description a new system for classifying chipped stone artifacts has come into being. This new system is the behavioral or technological typology (see Sheets, 1975a). The chipped obsidian artifacts from Chiapa de Corzo were reevaluated in the light of this general system.

In the following discussion, the basic concepts of behavioral typology, as it has been employed in Mesoamerica, will be presented as well as an example of its application to the Chiapa de Corzo obsidian artifacts. Two models for the obsidian industry will be presented; one for the Preclassic period and one for the later periods (mainly Classic).

\section{Behavioral Model}

As the name implies, a behavioral model is one that emphasizes the recovery of prehistoric behavior patterns. Basically, a behavioral model is a technological model. Changes in techniques of manufacture are indicative of "behavioral discontinuities" (Sheets, 1975a).

The classic example of a behavioral discontinuity for Mesoamerican core/blade industries is the change from percussion flaking to pressure 
flaking. This is an obvious change in behavior on the part of the prehistoric artisans. The behavioral shifts or "discontinuities" can be discerned through examination of the technological attributes of artifacts and debitage from each manufacturing stage. All identifications of technological attributes are based upon analogy with experimentally replicated specimens (Collins 1975) such as has been presented by Crabtrec (1968). Thus, the purpose of the analysis is to determine the steps ("action sets") or techniques that the artisan went through to manufacture and use the tool.

The manufacturing process begins with selection of raw material and ends with the discard of a worn-out or broken tool. Once all of the sequential steps of the reduction process have been isolated, they are combined into a processual or behavioral model. The resultant model represents the structure of the prehistoric industry and shows the relationship between all of the artifact types (Shcets 1975a). The model, then, is a hierarchal representation of the reduction process of raw lithic material into finished tools by either percussion or pressure techniques.

The benefit of a technological analysis is that it is an "emic" or inherent taxonomic system (Sheets 1975a). Inferences of certain classes of past behavior, eg. stone tool manufacture and tool use, can readily be made from the data resulting from the analysis. In the following discussion such a behavioral model is presented for Chiapa de Corzo. The model is based on a preliminary examination of the obsidian artifacts from the site. A more detailed analysis, including all lithic materials, has yet to be completed. As stated previously, the material that was studied resulted from the numerous seasons of excavation at the site undertaken by the NWAF.

\section{Preclassic Model}

In the following discussion a model of the Preclassic obsidian industry (Escalera through Horcones) is proposed for Chiapa de Corzo. The model is based upon limited data since the phase associations of many of the artifacts have yet to be determined. The artifacts which are dated, through their associations with caches and burials, indicate the model described below. Preceding the presentation of the model is a brief description of the artifacts upon which the model is based. The model also follows the general outlines of that presented by Sheets $(1972,1975 \mathrm{a}, \mathrm{c})$.

The dominant form of obsidian found at Chiapa de Corzo is prismatic blades (Lee 1969). The percentage of obsidian debitage or 
wastage is very low; however, this is also true of most sites that are not close to obsidian outcrops. Also, the excavation of Chiapa de Corzo was carried out over a period of several years. During that time the recovery procedures and criteria for artifact collection were not uniform. Therefore, a collection bias, not of the authors' making, may be partially responsible for the low percentage of obsidian flakes.

Other flake and blade types found in Preclassic contexts are macroflakes, macroblades, small percussion blades, debitage and stemmed daggers. No macrocores were found but the evidence suggests that most, if not all, of the artifacts were derived from macrocores (see Hester 1972 for definition). The terms macroflakes and macroblades are the equivalent to what Sheets calls large flakes and large blades $(1972,1975 \mathrm{a})$. The term small percussion blades is used as in Sheets $(1975 \mathrm{~b})$; debitage refers to wastage. Stemmed daggers have been described by Coe (1957). Evidence from Chiapa de Corzo indicates that the term "dagger" is inappropriate for this artifact type. In the following paragraphs a new term for this artifact type and reasons for it will be presented.

One "stemmed dagger" was found in Tomb 1 (Horcones phase) at Chiapa de Corzo. Lowe and Agrinier describe the enterment and associated artifact as follows:

...The body rested on a mat or some type of litter, evidenced by a thin coating of carbonized material found beneath the skeleton. At his right hand was placed a cane-shafted, perhaps ceremonial, lance; this was fitted with a huge prismatic obsidian blade measuring $31 \mathrm{~cm}$. from its ground stem to its unretouched tip (Plates 17 , e; $19 \mathrm{c}, \mathrm{c})$. The apparently cruciform shank of the lance was studded with 56 shark teeth (Pls, 18, f; 19 d). A few of these teeth bore double perforations, but most seem to have been attached to the shaft by means of cement or gum of some sort. (1960: pp. $40,42)$.

The spear shaft was apparently also covered with cinnabar (Lowe and Agrinier 1960: Fig. 36; p. 40).

The evidence from the Tomb 1 find suggests that these artifacts were lance tips. Most probably such lances were ceremonial or symbols of rank. For these reasons, the authors suggest that the term dagger be dropped and a new term used in its place. The term adopted here is "tanged macroblade". This follows Sheets' term of tanged large blades (1978). Since the term macroblade has been adopted to replace the term large blade (see Sheets 1975a), the term tanged macroblade is the logical outcome of this change as applied to this artifact type. 


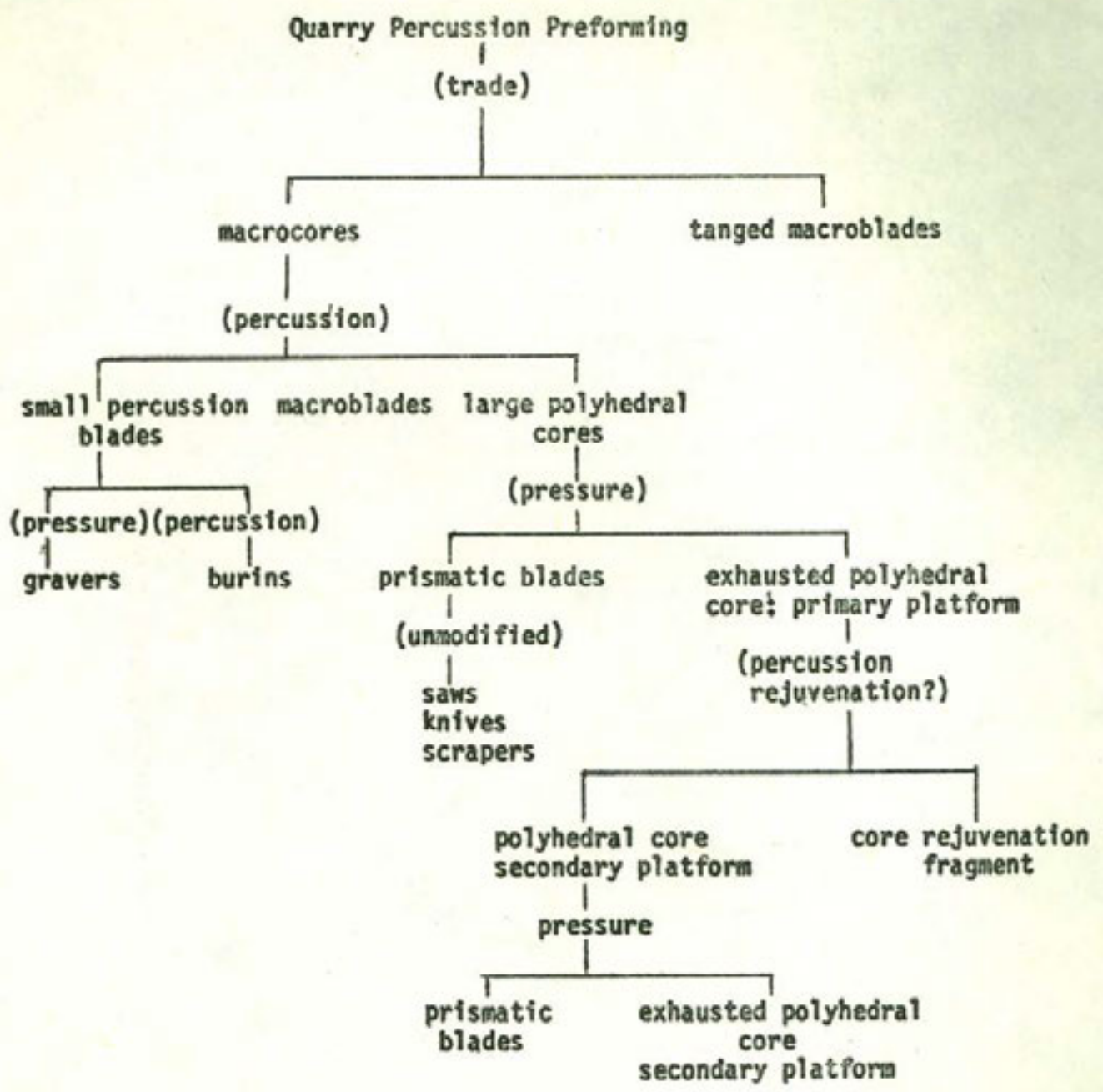

Frourz 1. Preclassic Model of Chiapa de Corzo Obsidian Industry. The question on the percussion rejuvenation technique arises because of the unknown date of some of the core rejuvenation fragments. 


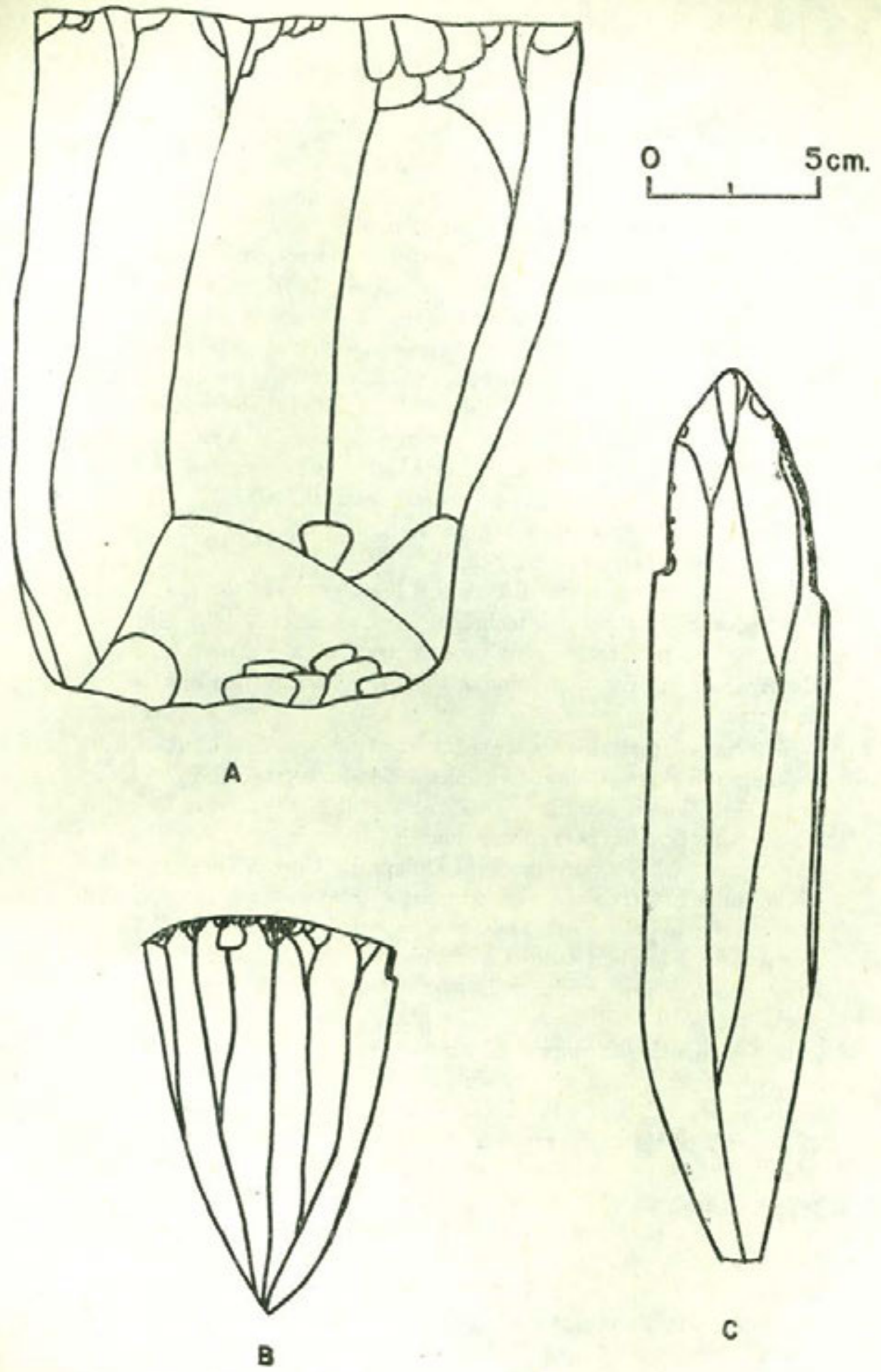

Fuourg 2, a, Macrocore in Tuxtla Gutierrez Regional Museum.

b. Large polyhedral core also from Tuxtla Museum.

Estudios de Eultuangrad macroblade fifom Chiapa de Corzo.

Instituto de Investigaciones Filológicas/

Centro de Estudios Mayas, UNAM

http://www.iifilologicas.unam.mx/estculmaya/ 
The artifact types found in Preclassic contexts suggest that macrocores were the form of imported obsidian (see Fig. 1 for model). Macrocores are defined as large cores which have been prepared by percussion by the removal of a platform flake and then a series of macroflakes (Clark 1978). Five macrocores have been described for the Mesoamerican area (Hester 1972, Clark 1977a). One found in the regional museum in Tuxtla Gutierrez is illustrated in Fig. 2.

Macrocores are reduced by percussion to form large polyhedral cores. By-products of this process are macroblades, macroflakes and small percussion blades. As mentioned above, all of these artifact types are found in Preclassic contexts. From this data it is inferred that macrocores were the form of imported obsidian. Also, the presence of a macrocore in the Tuxtla Gutierrez Museum (Clark 1977a) is taken as further evidence of the import of macrocores into the Central Depression of Chiapas in early times.

Once the large polyhedral core has been produced by percussion, it is reduced by a presure technique such as described by Crabtree (1968). The product of this process are the ubiquitous prismatic blades which are the most common form of obsidian found at Chiapa de Corzo.

Five tanged macroblades were found at Chiapa de Corzo, two of obsidian and three of chert (Agrinier 1964; Lowe and Agrinier 1960; Lee 1969). One is illustrated in Fig. 2 c. All of them were found in Guanacaste or Horcones phase burials. It is improbable that the tanged macroblades were made at Chiapa de Corzo. The larger size of the tanged macroblades, in comparison to macrocores suggests that they were made elsewhere and were imported into Chiapa de Corzo readymade. The chert tanged macroblades most probably came from Belize where recent evidence has been found of an extensive chert workshop (Wilk 1976).

In the model, the import of macrocores and tanged macroblades is shown as separate. Quite possibly the import of tanged macroblades was limited to the Late Preclassic (following the chronology in Lowe 1978), whereas macrocores were imported at least as early as the Middle Preclassic until Protoclassic times. The model (see Fig. 1 for dendritic diagram), also shows that the prismatic blades were further modified, in some cases, to form other specialized tools such as burins and gravers (see Fig. 3 for examples of these tools). Very few intentionally retouched tools were found at Chiapa de Corzo. Generally, the various flakes and blades resulting from the reduction process were used without further modification. 


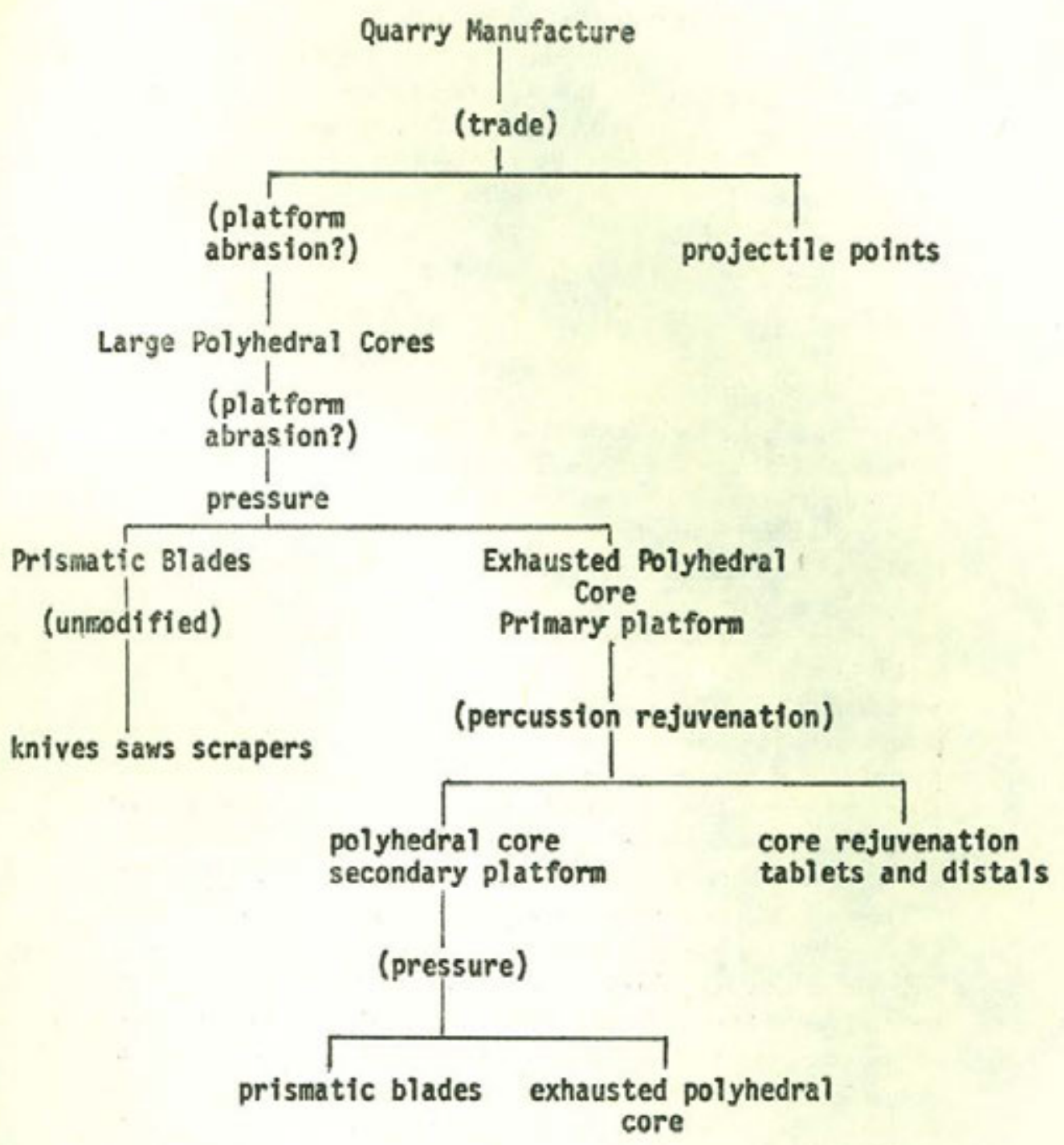

Fucure 3. Classic Period Obsidian Industry for Chiapa de Corzo. The representation is schematic in that the large polyhedral cores and projectile points probably came from different quarries. 
As mentioned in the previous section, a behavioral model ends with the discard of the worn-out tools. Unfortunately, no information is available from Chiapa de Corzo concerning discard patterns.

In summary, during the Preclassic period macrocores and tanged macroblades were imported into Chiapa de Corzo. The macrocores were further reduced by percussion and then pressure techniques to create a variety of flakes and blade types. As explained below, this differs from the Classic period obsidian industry mainly in the form of imported obsidian.

\section{Classic Model}

More information concerning the Chiapa de Corzo obsidian industry is available for the Classic period than for the Preclassic period. Most of this information comes from the "peanut field" excavations. The artifacts recovered from this excavation will be discussed below. The model based upon the analysis of these artifacts will follow.

Most of the material that was analyzed from a technological perspective came from the "peanut field" excavations. The "peanut field" excavations consist of a large trenche excavated between mounds 5 and 6 in what was then a peanut field. The trench yielded obsidian workshop debris. Whether the debris is from a workshop in the immediate area or redeposited has not been determined (see Sheets 1972 for an example of redeposited workshop debris). The workshop debris is associated with the Middle Classic period (Gareth W. Lowe, personal communication). The justification for the workshop interpretation will be given below. (This information is also summarized in Table 1).

The total collection from the peanut excavation numbers 179 pieces. Of these, 90 are prismatic blades or fragments, and 89 are cores or core-related debitage. This is an almost perfect $50-50$ split. The high percentage $(49.8 \%)$ of cores and core-related debris (i.e., core fragments, core rejuvenation flakes, plunging blades, and debitage) to prismatic blades, indicates a locus of prismatic blade manufacture. In one of the few comparative models available for prismatic blade manufacture, Sheets and Muto were able to produce 89 blades from one core (1972). They consider their efforts very conservative since their blades were thicker than normal prismatic blades found at Mesoamerican sites and their core somewhat smaller. Their efforts also produced two plunging blades as well as several debitage flakes resulting from the correction of errors. Such common errors include 


\section{TABLE 1: Peanut Field Totals}

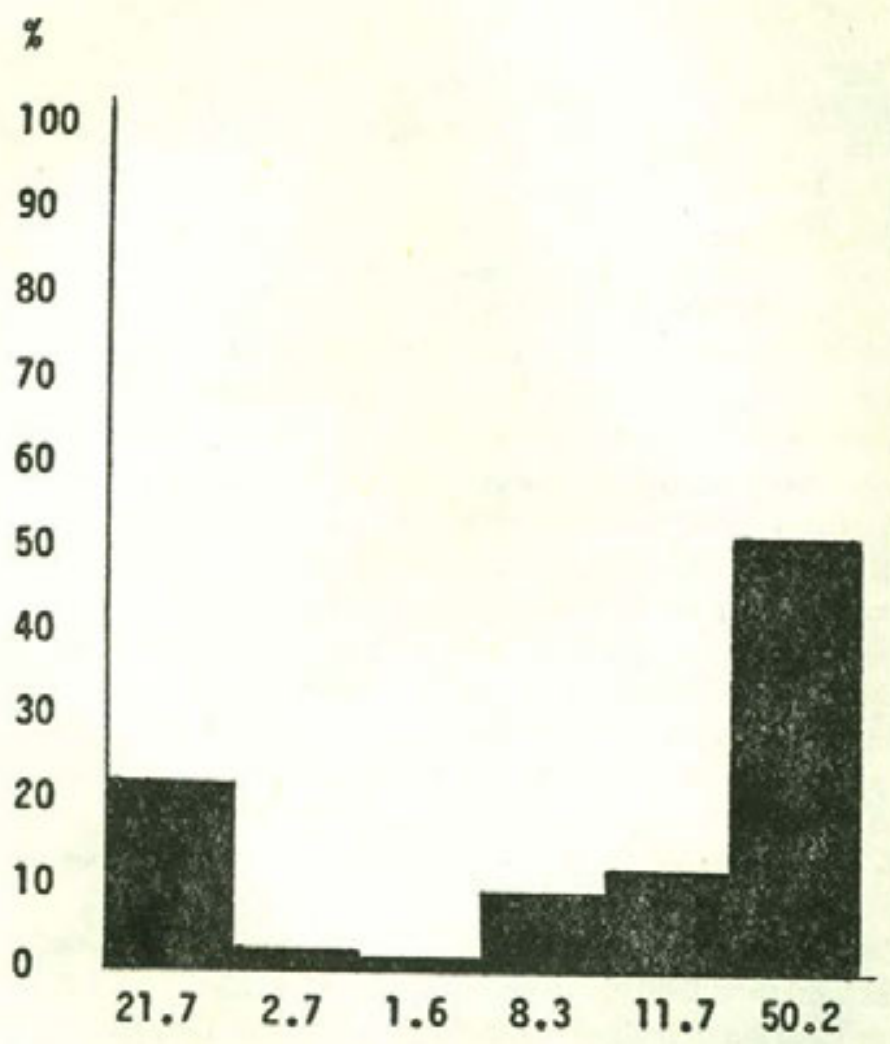

Total 179

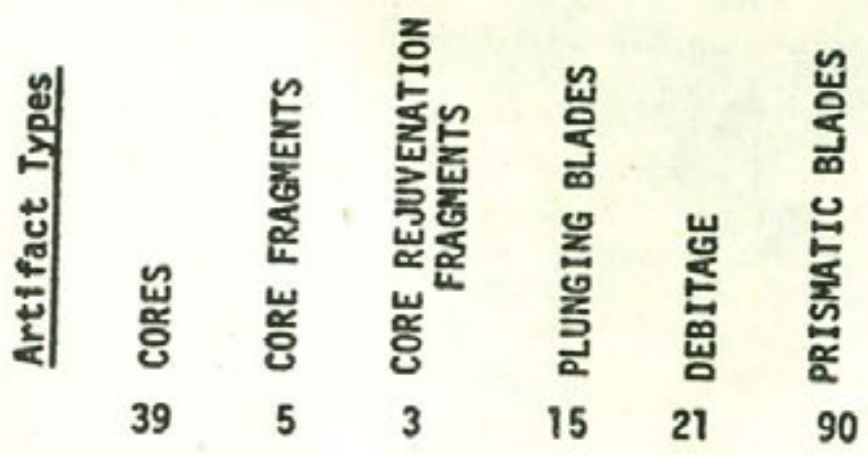


hinge fractures and step fractures (Crabtree 1968). The following quantities of artifact types are taken from the data presented by Sheets and Muto (1972).

1 exhausted core

2 plunging blades

? several debitage flakes
89 prismatic blades (if sectioned

this would be $178-267$ blade fragments)

The ratio of core and core-related debitage to prismatic blades is about $5: 90$ or $1: 18$.It is expected that this ratio will differ from artifact ratios characteristic of prehistoric workshops because of several factors: 1) the ability of the artisans to produce prismatic blade (i.e., low failure rate); 2) the sale or trade of the blades (removing them from the workshop); 3) workshop cleaning (relocation of debris); 4) sectioning blades; 5) ceremonial caching; etc. In fact, if one assumes all of the blades are sold, this leaves only the exhausted core and debitage. Other information indicates that this is not the case. Sheets found numerous prismatic blades in his Bustamante, El Salvador workshop debris; a much higher percentage than that found at Chiapa de Corzo (maybe due to the proximity to raw materials). Early Spanish accounts describe the blade-making process and mention that some blades were broken during manufacture (see Torquemada, Motolinía, and Hernández for the Aztec technique). They also indicate that prismatic blades of obsidian were very cheap. The cheapness of the blades could account for their apparent discard with the other useless workshop debris. However, the situation described for the Aztecs is probably not really comparable to that at Chiapa de Corzo. The Aztecs had ready access to abundant, fine quality obsidian, whereas the inhabitants of Chiapa de Corzo did not. Even so, it is logical to assume that broken or defective blades were thrown away with the rest of the trash, albeit in small numbers, or that the blades represented are household trash associated with the numerous discarded pot sherds.

The total number of exhausted polyhedral cores recovered from the "peanut field" excavation is 39. Five core fragments and three possible core rejuvenation flakes also form part of the collection. Therefore, a total of 47 cores or core fragments are represented. Using a very conservative estimate of 100 blades per core (see Sheets and Muto 1972), one could expect 4,700 whole prismatic blades from the 47 cores or 9,400 to 14,100 blade fragment (estimates based upon breakage of blades in half or in three pieces as was usually the case -proximals, medials, and distals). The total amount of obsidian 
recovered from Chiapa de Corzo totals less than 1,500 pieces, well within the number of blades which could have been produced from the 47 exhausted polyhedral cores. However, surface obsidian is quite abundant at Chiapa de Corzo. Therefore, the small number of prismatic blades recovered from the site may be due to the then recognized excavation techniques of no screening of mound fill and of digging in the ceremonial center. The numerous blades suggested by the number of cores may yet be found in association with the domestic units where prismatic blades were probably used as multipurpose tools.

The above discussion has been based on several implicit assumptions. First, it is obvious that obsidian was imported into Chiapa de Corzo since there are no sources nearby. A trace element analysis has not yet been performed upon this obsidian but it appears from visual inspection that several sources are represented. For example, there are nine pieces of the green obsidian which is characteristic of the Pachuca source. Clear gray, opaque gray, black, and black banded obsidian are also represented.

As mentioned above, obsidian imported during the Preclassic was in the form of macrocores. During the Classic period this changed to just the importation of large polyhedral cores. The same Classic period model has been found to be true of other sites as well (Johnson 1976). Eight such large polyhedral cores are presently in storage in the Tuxtla Gutiérrez Regional Museum. The vital provenience data are missing, but it is probable that they were found in the Central Depression near Tuxtla Gutiérrez. These cores are much smaller than macrocores and represent the transitional stake between percussion and pressure flaking. Therefore, these cores were prepared elsewhere (quarry) for the process of pressure flaking (Clark 1978). This explains the absence or small amount of core preforming debitage and percussion blades found in Classic deposits. The behavioral model for Chiapa de Corzo (Classic period) is as shown in Fig. 3.

In essence, this model is that proposed by Sheets, except without the preliminary stages of macrocore manufacture (Sheets 1972, 1975a, c). The difference reflects the different forms of obsidian at the beginning stages of the reduction process. Many specific aspects of the model are based upon manufacturing errors and recovery tech. niques.

The cores from Chiapa de Corzo are unique; they are small enough to be classified as microcores (see Fig. 4). Most are conical in shape and average $3-5 \mathrm{~cm}$. in length. The platforms are round to ovoid. All are heavily abraded or "frosted", a technique that makes blade detachment easier (Crabtree 1968). These cores have not been 

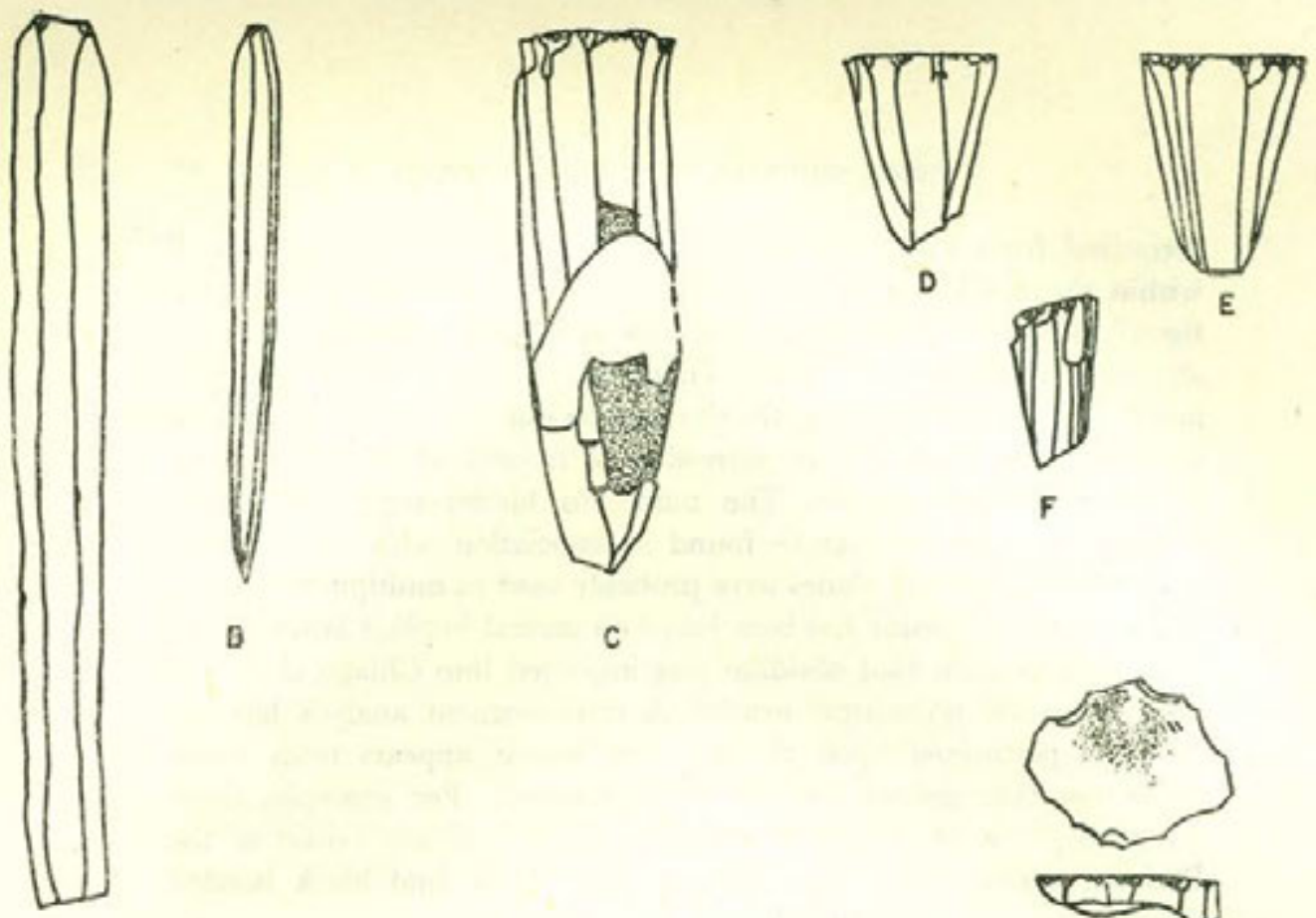

E

D

c

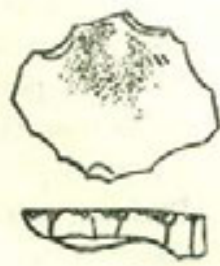

G

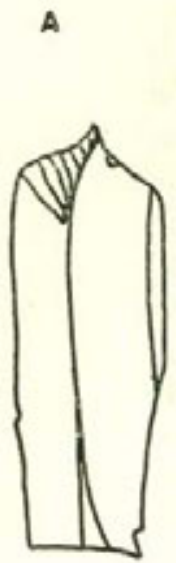

H

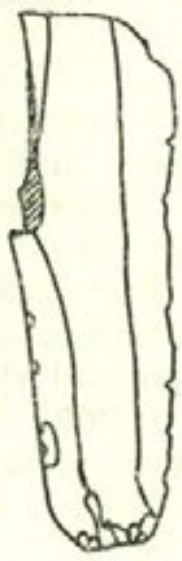

I

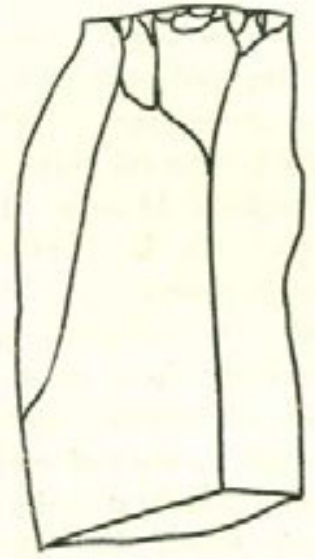

J
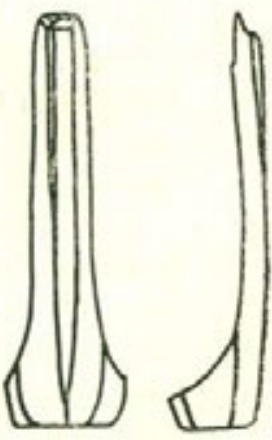

K

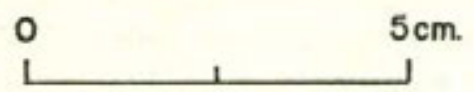

Froves 4. Artifacts from Chiapa de Corzo.

A-B. Whole prismatic blades.

C. Exhausted polyhedral core used as an abrader (broken into two pieces).

D-F. Exhausted polyhedral cores (microcores).

G. Core rejuvenation table from a polyhedral core.

H. Graver on small percussion blade.

I. Burin on small pereussion blade.

Estudios de Cultura Maya.

J. Proximal of macroblade.

Instituto de Investigaciones Filológicas/

Centro de Estudios Mayas, UNAM 
studied thoroughly; therefore, the basic descriptive data is not yet available. However, the smallness of all the cores indicates that perhaps special conservation techniques were in operation.

Several blades and blade fragments from Chiapa de Corzo show that at least two recovery techniques were used to repair mistakes made during blade removal. These same techniques are mentioned by Sheets and Muto:

One attempt at blade removal failed owing to the fact that insufficient force had been applied for the size of the platform and the intended blade. The force did create a bulbar fracture $1 \mathrm{~cm}$. deep at the proximal end without actually removing any material from the core. Successful recovery was achieved by seating the pressure tool above two ridges $1 \mathrm{~cm}$. to the left of the previous contact point, taking a relatively large platform $(0.3$ by $0.15 \mathrm{~cm}$.) and removing most of the fracture proximal area along with a complete blade... The blade carried two platforms and two bulbs, but examination of the compression rings and fissures on the ventral surface unequivocally indicate fracture of the blade itself deriving from the second platform. (1972: 632).

Another common mistake that plagues knappers is hinge and step fractures (Crabtree 1968). Several blades show that the ancients did away with hinge fractures by removing half of it with one blade and half with another. Possibly the other techniques mentioned by Sheets and Muto (1972) could have been used but the resultant debitage would be difficult to identify as such (see also Sheets 1972: 23).

Four examples of the "double-bulbed" blades which result in the manner described above have been identified in the Chiapa de Corzo material. One specimen was found in unmistakable association with workshop refuse. Each proximal end shows evidence of two bulbs on one blade (see Fig. 5). The proximal ends of these blades are about one and a half times as wide as they would normally be.

Another technique evident at Chiapa de Corzo and also mentioned for Palenque, is core reversal (Johnson 1976). In this technique the core is rotated $180^{\circ}$ and a blade is removed from what was normally the distal end of the core. (Sometimes a platform must be created at the distal end). This is very easy to identify on the blades by examination of the fissures (i.e., tiny hairline cracks on the lateral margins of the blades) which always point toward the direction of force (Crabtree 1968; J. B. Sollberger, personal communication). The significance of this technique has not been determined, but there are at least two possibilities. Such a technique could be used in removing hinge fractures although in most examples this is clearly not the case. 

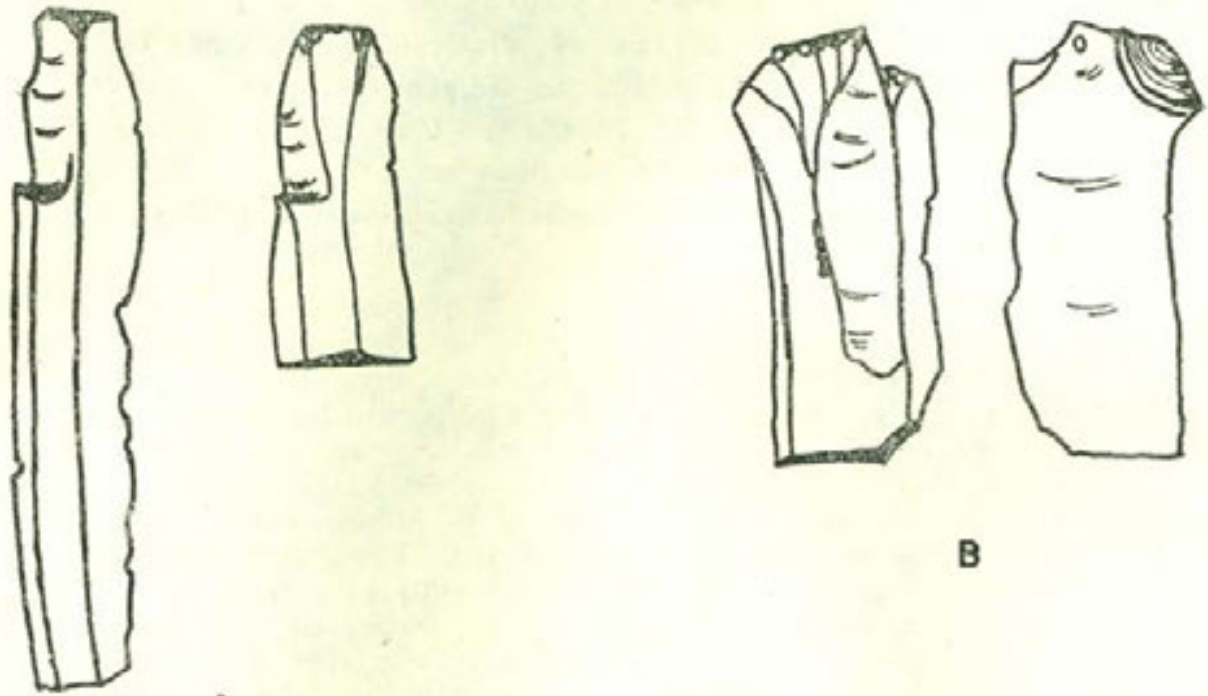

A
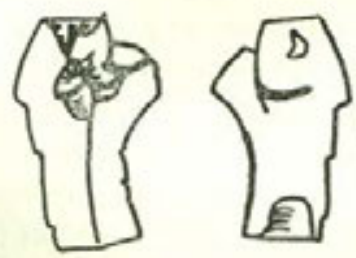

C
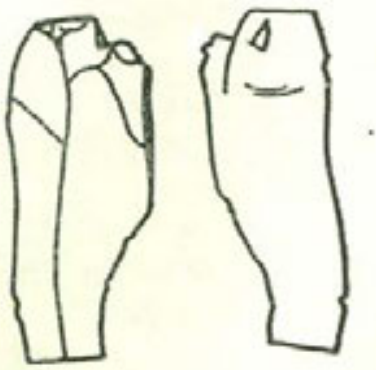

D

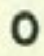

$5 \mathrm{~cm}$.

Figure 5. Artifacts from Chiapa de Corzo showing evidence of manufacturing errors and recovery techniques.

A. Prismatic blade showing hinge fracture removal by "side by side" technique.

B-D. Prismatic blades showing two bulbs on proximal end. 
Core reversal would also maintain straighter core sides and hence straighter blades (Crabtree 1968). If the latter were the case, then it would be a very significant technological innovation resulting in a more efficient blade. However, this technique was probably not used often since it is little represented in the artifact sample. All of these techniques are "recovery techniques" used in removing mistakes from the core surfaces. The number of such specimens indicate conservation of raw material. In areas where obsidian is abundant, the above mentioned mistakes are reason enough to discard the core.

Several other features of the Chiapa de Corzo sample are of interest. Three of the exhausted cores have been used as abrading tools. This is evident by large patches of frosted and smoothed areas on the core surface (see Fig. 4). The abrasion has worn away almost all traces of the blade scars. Willey describes such a core from Seibal (1978). Hester has also noted several examples of such cores (1973). The Chiapa de Corzo specimens compare with his Fig. 1 (1973: 149); only the abraded surface is slightly different. The abraded surface on the Chiapa de Corzo specimens is just like the abraded platform surfaces. The ones reported by Hester (1973) have a glossy shine and were apparently pot burnishing stones (p .150). The examples from Chiapa de Corzo could not have been used for pot burnishing; there is no associated gloss or shine with the abraded surface. It is probable that these obsidian abrading stones were used in some sort of lapidary process of working hard stone. Whitthoft (1968) shows examples of obsidian abraders that were used in working jade. The Chiapa de Corzo abraders have a similar abraded surface and could have been used in a similar manner. They might have been used in conjunction with the ear plug industry that is apparent from the numerous examples of "drill cores" (Lee 1969), found at Chiapa de Corzo.

As mentioned above, the platforms of all the Chiapa de Corzo cores have been thoroughly abraded. This abrasion weakens the surface tension of the core platform by causing tiny microcracks. All fracture is dependent upon microcracks or weak spots in the stone surface caused by impurities (Lawn and Marshall 1977). The abrasion of the platform creates numerous microcracks. This allows for greater control in flaking besides reducing the pressure or "load" needed to remove a blade (Lawn and Mashall 1977).

The process of thoroughly abrading the platforms is definitely a technilogical advance (see Crabtree 1968 and Sheets and Muto 1972). According to the evidence now available, this technique is mostly confined to the Late Classic and Postclassic periods (Rovner 1975, Willey 1978, MacNeish et. al. 1967, Sheets 1978). The technique is 
now being used as a horizon marker for the Postclassic. Sheets (1978) has noted that it appears earlier but only in small frequencies. It is interesting, therefore, that all the Chiapa de Corzo specimens are abraded and appear en masse at such an early date. The implications of this phenomenon should be given more serious investigation. Rovner places the origin of this technique between the Guatemalan Highlands and Central Mexican plateau; he postulates Veracruz (1975). However, Chiapas may be a more likely candidate.

One more phenomenon germane to the cores in question is that they are all conical in outline. Apparently this is the form of most large polyhedral cores (Sheets 1975a, Clark 1977b), but not exhausted cores. Most exhausted polyhedral cores are "bullet-shaped" or "cylin" drical" (e.g., see MacNeish et. al., 1967). During the process of blade removal, more is removed at the proximal end than the distal end because of the greater thickness of the bulb of pressure. For this reason, large polyhedral cores are conically shaped, being wider at the platform or proximal end than at the distal end. During prismatic blade removal, the two ends balance out and the core becomes cylindrical and straighter blades are produced (Crabtree 1968). Sometimes the proximal end becomes smaller than the distal end; the resultant core is teardrop-shaped. For these reasons it is interesting to find exhausted polyhedral cores that retain the.original conical shape (Sheet illustrates a similar core, 975a, c).

A clue to the phenomenon noted above may be found in the large number of plunging blades. A plunging blade is the result of too much downward pressure (Crabtree 1968). Such a blade removes the tip of the core (See Lee 1969 Fig. 112, n-s for examples). Most of the exhausted polyhedral cores show that the tip was removed by one or more plunging blades (Lee 1969: Fig. 112).

Core rejuvenation flakes were present in the original counts of the workshop debitage.. They result from an attempt to restore an exhausted polyhedral core to a condition where more prismatic blades can be removed. Such techniques are suggestive of conservative measures in regards to the obsidian supply. However, none of the cores show evidence of rejuvenation.

Other artifacts, besides the cores described above, which seem to be early at Chiapa de Corzo, are bifaces or projectile points (see Lee 1969: 157, Fig. 112 a-f). These are generally characteristic of the Late Classic or Postclassic periods (Sheets 1978; Willey 1978). No evidence for biface manufacture has been found at Chiapa de Corzo. Therefore, it is probable that these projectile points were imported (probably from the Mexican plateau). Two of the projectile points 
are made of the same obsidian which is an opaque cloudy gray; one is of Pachuca green obsidian. Both of these types of obsidian are rare at Chiapa de Corzo. A Mexican source is postulated for these points because of the apparently different kind of obsidian from which they are made and the fact that there is a tradition of projectile points in the Mexican plateau at this time period. This tradition is absent in the Maya Highlands at this same time period.

\section{Summary}

In the above description a model of the obsidian industry of Chiapa de Corzo was presented. It was shown that a major change took place in the industry between the Late Preclassic and Middle Classic. The change was a shift from the importation of macrocores and tanged macroblades to large polyhedral cores (and later finished bifaces). In general, the two models presented compare favorably to those described by Sheets for Bustamante $(1972,1975$ c) and Chalchuapa (1978). A major difference is the early occurrance at Chiapa de Corzo of polyhedral cores with abraded platforms and bifaces. It is hoped that similar behavioral analyses will eventually be performed on other lithic collections in areas adjacent to Chiapas. It can then be determined whether or not these features are indeed earlier at Chiapa de Corzo than other sites in Mesoamerica.

\section{BIBLIOGRAPHY}

Agrinier, Pierre

1964 "The Achaeological Burials at Chiapa de Corzo and their Furniture". Papers of the New World Achaeological Foundation, No. 16. Provo.

Carrol, A. and L. Coutier

1932 "Contribution a T'étude de la taille de l'obsidienne au Mexique".

Chark, John E. Bulletin, Societé Prehistorique Française 29:12: 579-82.

1977 a "A macrocore in the Regional Museum in Tuxtla Gutierrez, Chiapas, Mexico". Lithic Technology, Vol. VI, No. 3.

$1977 \mathrm{~b}$ "Large Polyhedral Cores from Mesoamerica". Ms on file at New World Achacological Foundation, San Cristóbal de Las Casas, Chiapas, México.

1978 "Guatemalan Obsidian Sources and Quarries: Additional Notes". (in press).

Cor, W.

1957 "A distinctive artifact common to Haiti and Central America". American Antiquity, 22:280-82. 
Collnes, Michaet B.

1975 "Lithic Technology as a Means of Processual Inference" in Swanson (ed) 1975.

Crabtree, Don E.

1968 "Mesoamerican polyhedral cores and prismatic blades". American Antiquity, 33:446-78.

Fex.duan, L,

1971 "Of the stone called iztli". American Antiquity, 36:213-14.

Hernández, Francisco

(see Marcou 1921; Cabrol \& Loutier 1932; Feldman 1971 for translations).

Hester, Thomas R.

1972 "Notes on large obsidian cores and core-blade technology in Mesoamerica". Contributions. University of California Archaelogical Research Facility, 14:95-106.

1973 "The reuse of obsidian blade cores in Mesoamerica". The Masterkey, 47:149-52.

Hestre, Thomas R. and Norman Hammond (eds.)

1976 Maya Lithic Studies: papers from the 1976 Belize Field Sympos. ium Special Report No. 4, Center for Archaeological Research,

JoHNson, JAY The University of Texas at San Antonio.

1976 Chipped stone artifacts from the Western Maya periphery. $\mathrm{Ph}$. D. dissertation. Southern IIlinois University.

LAWN, B. R. AND D. B. MArshalt.

1977 "Mechanisms of Micro-Contact Fracture in Brittle Solids". Paper presented at the Simon Fraser Conference of Lithic Use Wear,

Lee, Thomas A., JR.

1969 "The artifacts of Chiapa de Corzo, Chiapas, Mexico". Papers of the New World Achaeological Foundation. No. 26. Provo.

LOWE, GARETH W.

1978 "Eastern Mesoamerica" Chronologies in New World Archaeology. Academic Press, Inc., New York, San Francisco, London.

Lowe, Gareth W. and Prerere Acrinizr

1960 "Mound 1, Chiapa de Corzo, Chiapas, Mexico". Papers of the New World Achacological Foundation, No. 8. Provo.

MacNeish, R. S., Antoine Nel.ken-Ternes And Irmonrd

WeITLANER DE JoHNSON

1967 The Prehistory of the Tehuacan Valley Vol. 2: The Nonceramic Artifacts. University of Texas Press. Austin.

Marcov, Ph.

1921 "Procède de Azteques pour la taille par éclatement des couteaux ou rasoirs d'obsidienne". Journal de la Societé des Americanistes de Paris, 13 (n. s.): 17-24.

Motolinia, Fray Tokmo

1973 Historia de los indios de la Nueva España. Con notas, etc. de Edmundo O'Gorman, Editorial Porria, S. A., México.

ROVNER, IRWIN

1975 Lithic Sequences from the Maya Lowlands. Dissertation, University of Wisconsin. University Microfilms Reprint. 
Sheets, PAyson D.

1972 "A model of Mesoamerican obsidian technology .based on Preclassic workshop debris in El Salvador". Cerámica de Cultura Maya 8:17-33.

1975a "Behavioral analysis and the structure of a prehistoric industry". Current Anthropology 16:369-91.

1975b "A reassessment of the Precolumbian obsidian industry of E1 Chayal, Guatemala". American Antiquity 40:98-103.

$1975 \mathrm{c}$ "Un modelo de tecnologia mesoamericana de la obsidiana basada en desechos de un taller preclásico en El Salvador". América Indigena, Vol. XXXV, No. 4. (Reprint of article in Estudios de Cultura Maya, Vol. IX, 1973).

1978 The Prehistory of Chalchuapa, El Salvador, Vol. 2, Artifacts and Figureines. Co-authored with Bruce Dahlin. University of Pennsylvania Press.

Sheets, Payson D. and Guy Muto

1972 "Pressure Blades and Total Cutting Edge: An Experiment in Lithic Technology", Science 175:632-634.

Swanson, Eare. (Ed.)

1975 Lithic Tecnology: Making and Using Stone Tools, Mouton Publishers, the Hague, Paris.

Torqugmada, Fray Juan de

1975 Monarquia Indiana. Quinta Edición, Introducción por Miguel León Portilla, Editorial Porrúa, S. A., México .

WILx, RicHard

1976 "Work in Progress at Colha, Belize", 1976 in Hester and Hommond 1976.

WrLeY, GoRDON R.

1978 "Excavations at Seibal, Department of Peten, Guatemala. Artifacts". Memoirs of the Peabody Museum of Archaeology and Ethnology, Vol. 14, No. 1.

Wiттионт, JoнN

1968 "Flint Arrowpoints from the Eskimo of Northwestern Alaska". Expedition, 10(2):30-37. 